\title{
Shakespeare y la prodigiosa historia de Serratia marcescens como marcador biológico
}

\author{
WALTER LEDERMANN D.
}

\section{Shakespeare and the prodigious history of Serratia marcescens as a biological marker}

En una oportunidad anterior nos referimos a la participación que pudiera haber tenido la prodigiosina, el pigmento rojo de Serratia marcescens, en la caída de Tiro frente a Alejandro Magno, así como la relación de esta bacteria con Rafael, a raíz del milagro de Bolsena, donde la hostia goteó sangre y manchó el altar. Mencionamos también que tuvo una relación indirecta con Shakespeare y desde este gran dramaturgo retomaremos la historia, para referirnos al uso que tuvo la prodigiosina como marcador biológico y que hoy, conocedores del potencial patógeno de Serratia marcescens, nos pone los pelos de punta.

El pigmento en cuestión fue completamente extraído por Kroft, en 1902, y designado "prodigiosina", pero su estructura íntima sólo vino a quedar elucidada en 1960, gracias a Rapaport y Holden. Todavía ensangrentó al menos una hostia en 1910, en pleno siglo XX, en una iglesia de Nápoles, causando no poco revuelo. Sin embargo, ya identificado, los científicos habían encontrado para él un uso más ingenioso como marcador biológico. En 1906, a raíz de una epidemia de influenza en Inglaterra, se comisionó a M.H. Gordon para que estudiara la higiene en la atmósfera de la Cámara de los Comunes. Gordon, tras hacer gárgaras con un cultivo de Serratia, declamó trozos de Shakespeare ante la sala vacía, analizando luego, gracias al hallazgo de pigmento, hasta dónde había diseminado la bacteria. Nada le ocurrió a Gordon; al honorable cuerpo de los Comunes, tampoco. Quizás, el párrafo que Mr. Gordon declamó, arrojando rojas gotitas de Pflügge sobre los escaños desiertos, era el famoso parlamento al final del primer acto de Hamlet:

Horacio. -¡Oh, luz y tinieblas! ¡Pero esto es prodigiosamente extraño!

Hamlet. -Pues dale, por lo mismo, como a un extraño, buen recibimiento. ¡Hay algo más en el cielo y en la tierra, Horacio, de lo que ha soñado tu filosofía!

De allí en adelante continuó el empleo de la prodigiosina como marcador biológico, aunque en 1913, Woodward y Clarke habían descrito el primer caso clínico en que Serratia marcescens pudo jugar un papel patógeno: un paciente con bronquiectasia tenía expectoración roja, pero el examen microscópico no reveló eritrocitos, sino Serratia. Más de cuarenta años pasarían hasta que se publicaran, casi de manera simultánea, dos casos similares; en el segundo de ellos, Robinson y Wolley, quienes aún hablaban de Chromobacterium prodigiosum, propusieron el término de "pseudohemoptisis", que tuvo efímera existencia.

En 1920, estudiando la trasmisión de infecciones respiratorias a través de la portación manual, Cumming bombardeó con spray de Serratia la garganta, las encías y los labios de un contingente de soldados norteamericanos, recultivando luego la coloreada bacteria de manos y bocas de otros soldados, sin que ninguno enfermara. Tampoco enfermó ninguno de los voluntarios a quienes Mac Entegart y Portefield pusieron Serratia en las encías de dientes que iban a ser extraídos, recuperando la bacteria de hemocultivos en el $41 \%$ de ellos. Hoy en día, en que la endocarditis por $S$. marcescens tiene un considerable riesgo letal, la lectura de estas experiencias nos causa un estremecimiento de horror. ¿Y qué decir de los trabajos en que se introdujo la bacteria, deliberadamente, a través de catéteres en la vía urinaria? Hasta hace veinte años atrás, era práctica corriente en los cursos de microbiología que los ayudantes se frotaran las manos con cepas pigmentadas, para efectuar demostraciones prácticas de la diseminación bacteriana.

Pero faltaba el broche de oro, la más gigantesca e insensata dispersión bacteriana que registra la historia del mundo. En 1950, la Armada estadounidense quiso estudiar hasta qué punto la nación estaría expuesta en caso de una guerra bacteriológica, para lo cual dispuso que sus navíos fuesen mar adentro y arrojasen al mar grandes cantidades de Serratia marcescens. El viento formó aerosoles sobre las olas y los llevó sobre la costa de San Francisco, aislándose luego la bacteria de muestras tomadas hasta 80 metros tierra adentro. No parecía gran cosa, pero un año después hubo once casos de infección urinaria por esta bacteria en un hospital universitario de la ciudad, falleciendo también un paciente en el primer caso de endocarditis fatal por S. marcescens. En el mismo año se habían hecho otros experimentos con aerosoles en los condados Calhoun (Alabama) y Key West (Florida), en coincidencia con los cuales la incidencia de neumonía alcanzó cifras record en ambos.

Aun conociendo lo ocurrido, la Armada repitió sus experimentos en 1952, mereciendo la severa críti- 
ca del senador Richard Schweiter durante las audiencias públicas conducidas en 1977 por el Subcomité del Senado para Salud e Investigación científica, ocasión en que se señaló que se había usado bacterias sin analizar de manera exhaustiva su posible potencial patógeno, en experiencias mal dirigidas y que, a la postre, escasa información útil pudieron proporcionar. De hecho, experiencias con aerosoles habían continuado realizándose hasta 1968, y sólo un año después, durante la administración de Richard Nixon, Estados Unidos renunciaría a la guerra biológica, terminando S. marcescens su carrera marcadora. Le resultaba difícil a la Armada defender en 1977 hechos ocurridos 25 o 26 años atrás, pero el CDC de Atlanta vino indirectamente en su defensa, demostrando que, en un centenar de brotes de infecciones por Serratia marcescens producidos en EE.UU. después de esta discutida experiencia, no se había aislado ninguna cepa del serotipo O 8: H 3 / biotipo A 6 / fagotipo 678, caracteres que poseía la cepa empleada por la Armada. En una carta enviada a Lancet cuando se ventilaban las audiencias en el Senado, señala que "de más de tres mil cepas norteamericanas serotipificadas desde 1950, el serotipo O 8: H 3 se ha encontrado sólo siete veces"... No obstante, este vilipendiado serotipo iba a reaparecer en Norteamérica en la forma más sorprendente, constituyendo el detectivesco "caso del pañal rojo".

El niño nació en el Hospital Universitario de Wisconsin, el 27 de noviembre de 1954, pesando 3.410 gramos. Hijo de un profesor de genética de la misma Universidad, lucía enteramente normal y pudo ir a casa con su madre el séptimo día. Allí comenzaron a notar que, pese a tener deposiciones normales, los pañales se ponían rojos luego de ser arrojados al receptáculo proporcionado por la lavandería. Se investigó la presencia de uratos, con resultados negativos. La lavandería enviaba los mismos receptáculos a otros 800 niños y en ninguno de ellos se presentaba el mismo fenómeno. El niño estaba sanísimo; sin embargo, se hizo coprocultivo, que demostró la presencia de Serratia marcescens en cultivo puro. Esta identidad fue confirmada nada menos que por el Dr. Ewing, en el CDC de Atlanta, e identificada como serotipo O 38 (O 8: H 3 lo desglosa Farmer $i$ ?). El niño fue tratado con sulfas, pero su mamadera no fue esterilizada en forma terminal; además, en un extraño intento para normalizar su flora intestinal, se agregaron a su alimentación cereal y frutas... ¡a los 28 días de vida! Pese a esta medida extrema, sólo a las seis semanas aparecieron otras bacterias en las deposiciones, en tanto que la Serratia se demoró siete meses en hacer mutis.

La investigación epidemiológica de este caso abarcó el estudio de sus familiares y de otros niños que fueron sus contactos en la maternidad, sin que se encontrase en ellos la roja bacteria. Por último, se descubrió que en el laboratorio de bioquímica, en un edificio ubicado a 500 yardas de distancia (unos 450 metros), se estaba trabajando con aerosoles de Serratia marcescens, los que ya habían contaminado el laboratorio de genética. El serotipo de las cepas encontradas en ambos laboratorios era el mismo que el aislado del intestino del lactante. Waisman y Stone, al publicar el caso, crearon el efímero síndrome del pañal rojo. ¡Qué manera de buscar la inmortalidad a bajo costo!

Después de la endocarditis fatal de 1951, una solución intravenosa contaminada provocó un brote de meningitis en pediatría, iniciando la colorina bacteria su exitosa carrera como patógena oportunista intrahospitalaria, a tal punto que nadie osaría actualmente usarla como "marcador biológico".

Una larga y dramática historia la de Serratia marcescens, en la que nos han acompañado, a la par con ingeniosos científicos del pasado, las figuras legendarias de Pitágoras, Alejandro, Rafael y Shakespeare, y en la que hemos navegado desde el Arno, con el enigmático Serafino Serrati en su bote a vapor, hasta la bahía de San Francisco, para arrojar la bacteria al mar desde los majestuosos buques de la Armada norteamericana.

Y nos preguntamos... ¿ ¿cuál será la próxima sorpresa que nos deparará esta prodigiosa criatura?.

\section{Bibliografía}

1.- Cullen J C. The miracle of Bolsena. Growth of Serratia on sacramental bread and polenta may explain incidentes in medieval Italy. ASM News 1994; 60 (4): 187-91.

2.- Farmer J J, Davis B R, Grimont P A D et al. Source of american Serratia. Lancet 1977; 2: 459-60.

3.- Gale D, Lord J D, Durham N C. Overgrowth of Serratia marcescens in respiratory tract, simulating hemoptysis. JAMA 1957; 164 (12): 1328-31.

4.- Gaughran E R L. From superstition to science: The history of a bacterium. Trans NY Acad Sci 1969; 31: 3-24

4.- Ledermann W. Pitágoras, Alejandro, Rafael y la Serratia marcescens. Rev Chile Infect 1994; 11: 23-5.

6.- Robinson W, Woolley P B. Seudohaemoptysis due to Chromobacterium prodigiosum. Lancet 1957; April 20: 819-20.

7.- Shakespeare W. Hamlet. En Obras Completas, Aguilar, Madrid 1964; pp: 1346.

8.- Waisman H A, Stone W H. The presence of Serratia marcescens as the predominating organism in the intestinal tract of the newborn. The occurrence of the "Red Diaper Syndrome". Pediatrics 1958; 21: 8-12.

9.- Yu V L. Serratia marcescens. Historical perspective and clinical review. N Engl J Med 1979: 300 (16): 887-93. 